\title{
Fatores de risco associados à infecção viral (BoHV-1 e BVDV) em rebanhos leiteiros mestiços com problemas reprodutivos, no município de Uberlândia, MG
}

\author{
[Risk factors associated with viral infections (BoHV-1 and BVDV) in crossbreed \\ dairy herds with reproductive failures, Uberlândia, $M G]$ \\ V.M. Barbosa ${ }^{1}$, C.C. Gondim ${ }^{1}$, N.R. Nasciutti ${ }^{1 *}$, P.M. Oliveira ${ }^{1}$, A.A. Alfieri ${ }^{2}$, \\ J.T.T. Fritzen ${ }^{2}$, S.A. Headley ${ }^{2}$, A.M. Saut ${ }^{3}$, F.T. Berssaneti ${ }^{3}$, J.P.E. Saut ${ }^{1}$
}

${ }^{1}$ Faculdade de Medicina Veterinária - Universidade Federal de Uberlândia - Uberlândia, MG

${ }^{2}$ Universidade Estadual de Londrina - Londrina, PR

${ }^{3}$ Universidade de São Paulo - São Paulo, SP

V.M. Barbosa

https://orcid.org/0000-0001-7056-3069 C.C. Gondim https://orcid.org/0000-0002-8136-7300 N.R. Nasciutti

https://orcid.org/0000-000 1-9608-7072 P.M. Oliveira

https://orcid.org/0000-0001-8024-5515 A.A. Alfieri

https://orcid.org/0000-0002-7024-4487 J.T.T. Fritzen

https://orcid.org/0000-0003-4635-5512

S.A. Headley

https://orcid.org/0000-0002-1614-0185 A.M. Saut

https://orcid.org/0000-0002-8775-7385 F.T. Berssaneti https://orcid.org/0000-0002-8604-1887 J.P.E. Saut

https://orcid.org/0000-0002-0860-5413

Com frequência, infecções virais são associadas a problemas da reprodução em rebanhos de bovinos de corte e leite de todo o mundo. Este estudo teve como objetivo avaliar variáveis de manejo que possam constituir fatores de risco da infecção por BoHV-1 e/ou por BVDV em rebanhos leiteiros com histórico de problemas da reprodução em vacas mestiças em manejo extensivo e sem histórico de vacinação prévia para o controle de IBR e BVD. Anticorpos neutralizantes anti-BoHV-1, anti-BVDV e para ambos os vírus simultaneamente foram identificados em 62,5\% (165/264), 45,1\% (119/264) e 31,4\% (83/264), respectivamente, das amostras analisadas. Os fatores de risco associados à infecção por BoHV-1 foram rebanhos com número total de fêmeas superior a 100, presença de ordenha mecânica, não utilização de inseminação artificial na reprodução e a compra infrequente de animais. Para BVDV, os fatores de risco foram aptidão mista (leite/corte) do rebanho, presença de ordenha mecânica, ausência de quarentena para os animais recém-adquiridos, presença de piquete de parição e a não utilização de inseminação artificial. Para a infecção simultânea (BoHV-1/BVDV), a presença de ordenha mecânica aumentou o risco em 3,36 vezes, e o uso de inseminação artificial reduziu em $56 \%$ o risco de infecção nos rebanhos avaliados.

Palavras-chave: bovinos, IBR, BVD, risco sanitário, vírus-neutralização

\begin{abstract}
Viral infections are frequently associated with reproductive problems in dairy and beef cattle worldwide. The aim of this study was to verify managerial practices that may constitute risk factors associated with infection by BoHV-1 and/or BVDV in dairy herds with a history of reproductive disease in extensively reared dairy cows without a previous history of vaccination against IBR and BVD. Neutralizing antibodies anti-BoHV-1, anti$B V D V$ or both were detected in $62.5 \%$ (165/264), 45.1\% (119/264), and 31.4\% (83/264), respectively, in the samples analyzed. The risk factors associated with infection by BoHV-1 were herds with more than 100 cows, the presence of mechanical milking, the non-utilization of artificial insemination, and the infrequent acquisition of animals. Risk factors associated with BVDV were dual-purpose herds (milk and beef), these include the utilization of mechanical milking, absence of quarantine for newly acquired animals, the presence of picket calving, and the absence of artificial insemination. For simultaneous infections by both viruses (BoHV-1 and $B V D V)$ the use of mechanical milking increased the chance of infection 3.36-fold while the use of artificial insemination reduced the risk of infection by $56 \%$ in these herds.
\end{abstract}

Keywords: cattle, IBR, BVD, sanitary risk, virus neutralization

\section{INTRODUÇÃO}

O Brasil está entre os países de destaque na cadeia produtiva do leite (USDA, 2015). Apesar da produtividade média dos rebanhos não ser

Recebido em 28 de setembro de 2017

Aceito em 10 de dezembro de 2018

*Autor para correspondência (corresponding author)

E-mail: nayaranasciutti@yahoo.com.br ainda a ideal, o número de rebanhos leiteiros e de vacas ordenhadas faz com que o país seja o quinto produtor mundial de leite. $\mathrm{O}$ estado de Minas Gerais é o maior produtor nacional, responsável por $26,4 \%$ do total da produção (Estatística..., 2017), e a mesorregião do 
Triângulo Mineiro, onde se localiza o município de Uberlândia, diferencia-se no estado tanto pelo maior volume de produção quanto por outras atividades vinculadas a essa importante cadeia produtiva do agronegócio brasileiro (Silva et al., 2012).

O alfa-herpesvírus bovino 1 (BoHV-1) e o vírus da diarreia viral bovina (BVDV), agentes etiológicos da rinotraqueíte infecciosa bovina (IBR) e da diarreia viral bovina (BVD), respectivamente, são causas frequentes de distúrbios reprodutivos em fêmeas bovinas, destacando-se as mortalidades embrionárias, seguidas de repetições de cios a intervalos irregulares, e fetais, acompanhadas de abortamentos. Em novilhas e vacas, o BoHV-1 pode ocasionar ainda infecções genitais que culminam em vulvovaginites e cervicites (Nandi et al., 2009). Na espécie bovina, as infecções por ambos os vírus também podem ser seguidas por outros importantes sinais clínicos, que, entretanto, não impactam na função reprodutiva (Sousa et al., 2013).

Exceto em alguns poucos países europeus com programas sanitários de erradicação de IBR e $\mathrm{BVD}$, os inquéritos soroepidemiológicos revelam que as infecções por BoHV-1 e BVDV estão amplamente disseminadas em rebanhos bovinos, tanto do Hemisfério Norte (Cowley et al., 2014; Segura-Correa et al., 2016), quanto do Hemisfério Sul (Dias et al., 2013).

Assim como em praticamente todo o mundo, também no Brasil, as infecções por esses dois importantes vírus estão amplamente disseminadas em pequenos, médios e grandes rebanhos bovinos de corte e de leite de todas as regiões geográficas do país (Médici et al., 2000; Flores et al., 2005). A alta soroprevalência desses agentes virais justifica a preocupação constante na identificação dos fatores de risco associados à infecção por BoHV-1 e BVDV (Barbosa et al., 2005; Chaves et al., 2010; Dias et al., 2013) nos rebanhos bovinos brasileiros, com o intuito de propor e avaliar medidas de controle e profilaxia e, consequentemente, reduzir os impactos e efeitos deletérios das infecções (Dezen et al., 2013).

Nesse contexto, o presente estudo teve o objetivo de avaliar o perfil sorológico para IBR e BVD em rebanhos bovinos leiteiros com histórico de problemas reprodutivos, provenientes do município de Uberlândia/MG, e, por meio da análise de um questionário epidemiológico, determinar variáveis do sistema de produção que possam constituir fatores de risco para as infecções.

\section{MATERIAL E MÉTODOS}

O estudo foi realizado no município de Uberlândia ( $\left(\begin{array}{llllll}18^{\circ} & 55^{\prime} & 07^{\prime \prime} & \mathrm{S} \text { e } 48^{\circ} & 16^{\prime} & 38^{\prime \prime} \\ \mathrm{W}\end{array}\right)$, situado no estado de Minas Gerais, região Sudeste do Brasil, microrregião do Triângulo Mineiro, entre os meses de janeiro a julho de 2013. Foram visitadas 20 propriedades leiteiras, distribuídas no perímetro rural de Uberlândia e nos quatro distritos do município (Martinésia, Cruzeiro dos Peixotos, Tapuirama e Miraporanga).

Apenas rebanhos leiteiros com histórico de problemas reprodutivos, definido por abortamento observado em qualquer fase de gestação e repetição de cio, foram incluídos no experimento. De cada rebanho foram selecionadas, aleatoriamente, de 13 a 14 vacas mestiças com aptidão leiteira, adultas, lactantes, nascidas na propriedade e com manejo extensivo de criação. Adicionalmente, somente rebanhos e animais sem histórico de vacinação contra IBR e BVD foram incluídos neste estudo. Destaca-se que, em todos os rebanhos avaliados, eram adotadas as medidas definidas do Programa Nacional de Controle e Erradicação de Brucelose e Tuberculose e do Programa de Erradicação da Febre Aftosa, de acordo com as exigências do Ministério da Agricultura, Pecuária e Abastecimento (Mapa) do Brasil.

Para identificar possíveis fatores de risco associados às infecções estudadas, foram obtidas, em todas as propriedades, informações referentes à característica de exploração pecuária (leite/mista); ao número total de fêmeas na propriedade ( $\leq 100$ ou $>100$ animais); ao número de fêmeas acima de dois anos $(\leq 50$ ou $>50$ animais); ao número total de animais no rebanho ( $\leq 100$ ou $>100$ animais); ao tipo de ordenha (manual ou mecânica); ao manejo reprodutivo (monta natural ou inseminação artificial); à compra frequente de animais (não/sim); à realização de quarentena (não/sim); à presença de piquete parição (não/sim); à presença de ovelhas (não/sim); à presença de ruminantes 
selvagens (não/sim); à presença de abortamentos no rebanho (não/sim); ao abortamento individual (não/sim); à repetição de cio individual (não/sim); e ao histórico de doenças respiratórias (não/sim).

Cada propriedade rural foi visitada apenas uma única vez, para a realização do questionário e de coleta das amostras. No total foram avaliadas 264 vacas leiteiras, sendo 65 provenientes do perímetro rural de Uberlândia e 199 dos distritos de: Martinésia $(n=42)$, Cruzeiro dos Peixotos $(\mathrm{n}=36)$, Tapuirama $(\mathrm{n}=28)$ e Miraporanga $(\mathrm{n}=$ 93). O sangue $(n=264)$ para obtenção do soro foi coletado por punção da veia caudal, sendo as amostras coletadas em tubos para coleta de sangue a vácuo sem anticoagulante (BD Vacutainer ${ }^{\circledR}$ ). As alíquotas de soro, devidamente identificadas, foram mantidas a $-80^{\circ} \mathrm{C}$ até a realização das técnicas sorológicas.

O teste de vírus neutralização (VN) para a detecção de anticorpos neutralizantes antiBoHV-1 e anti-BVDV foi realizado em células MDBK, utilizando-se $100 \mathrm{TCID}_{50 \%}$ das cepas Los Angeles e Singer, respectivamente, de acordo com o Manual de Teste de Diagnóstico e
Vacinas para Animais Terrestres da Organização Mundial de Saúde Animal (Manual..., 2015). Foram consideradas positivas as amostras de soro que apresentaram atividade neutralizante nas diluições $\geq 1: 2 \mathrm{e} \geq 1: 10$ para BoHV-1 e BVDV, respectivamente (Manual..., 2015).

Para avaliar a diferença na proporção de prevalência entre infecções por BoHV-1 e BVDV e distritos, com base na distribuição amostral, realizou-se uma estimativa intervalar da proporção populacional (Sweeney et al., 2013). Para verificar a relação dos fatores de risco com cada uma das variáveis de saída, foi realizada a análise de regressão logística, usando-se como benchmark um valor de $\mathrm{P} \leq 0,05$ e assumindo-se os pressupostos de Hosmer e Lemeshow (2004) e Hair et al. (2006). O modelo conceitual utilizado está descrito na Fig. 1. Utilizou-se a equação logística, segundo o software estatístico Minitab v.17, em que: $\mathrm{P}(1)=$ $\exp \left(\mathrm{Y}^{\prime}\right) /\left(1+\exp \left(\mathrm{Y}^{\prime}\right)\right)$, sendo $\mathrm{Y}^{\prime}=\beta_{0}+\beta_{1} \mathrm{X}_{1}+$ $\beta_{2} X_{2}+\ldots+\beta_{i} X_{i} ; B_{i}=$ coeficiente e $X_{i}=$ variáveis independentes. $\mathrm{O}$ estudo foi aprovado pela Comissão de Ética na Utilização de Animais (Ceua) da Universidade Federal de Uberlândia, registro $n^{\circ} 011 / 13$.
VARIÁVEIS DE ENTRADA (variáveis independentes)
VARIÁVEIS DE SAÍDA

(variáveis dependentes)

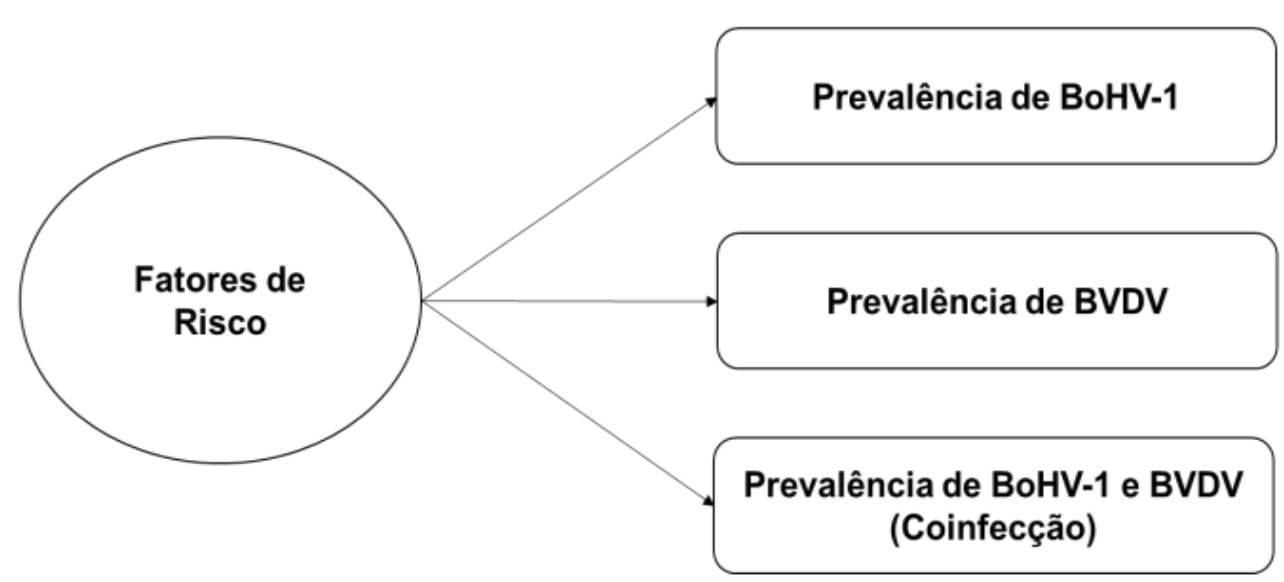

Figura 1. Modelo conceitual utilizado para avaliar os fatores de risco associados à infecção por BoHV-1 e BVDV. 


\section{RESULTADOS}

Foram identificados animais soropositivos tanto para BoHV-1 quanto para BVDV em todas as regiões geográficas amostradas no município de Uberlândia. A Tab. 1 apresenta a distribuição dos resultados do teste de VN para identificação de anticorpos neutralizantes anti-BoHV-1 e antiBVDV no soro das vacas incluídas neste estudo. Foram identificados animais soropositivos para os dois vírus avaliados, tendo sido observado que a soroprevalência para o BoHV-1 foi significativamente superior $\quad(\mathrm{P}=0,001)$ à encontrada para o BVDV.

Tabela 1. Soroprevalência para BoHV-1 e BVDV e para ambos os vírus em vacas leiteiras mestiças não vacinadas, no município de Uberlândia, Minas Gerais, Brasil, pela técnica de vírus-neutralização

\begin{tabular}{lcc}
\hline \multicolumn{1}{c}{ Tipo de infecção } & $\mathrm{N}$ (positivos) & Prevalência \% (IC)* \\
\hline BoHV-1 & $165 / 264^{\mathrm{a}}$ & $62,5(56,1-68,1)$ \\
BVDV & $119 / 264^{\mathrm{b}}$ & $45,1(39-51,3)$ \\
BoHV-1/BVDV & $83 / 264$ & $31,4(25,9-37,4)$ \\
\hline a,b Letras diferentes indicam diferença entre as frequências de BoHV-1 e BVDV; * IC= intervalo de confiança \\
(P<0,05).
\end{tabular}

A Tab. 2 apresenta a distribuição dos percentuais de soroprevalência para BoHV-1 e BVDV encontrados nos animais avaliados, de acordo com os possíveis fatores de risco incluídos na análise do questionário epidemiológico. Entre todas as 16 variáveis avaliadas, a análise dos resultados identificou quatro fatores de risco para a infecção por BoHV-1, cinco para BVDV e dois para a infecção simultânea por ambos os vírus (Tab. 3).

\section{DISCUSSÃO}

Com relação aos possíveis fatores de risco analisados neste estudo, rebanhos constituídos por reprodução realizada por monta natural, compra infrequente de animais, presença de ordenha mecânica e maior número de fêmeas foram importantes fatores de risco para as infecções por BoHV-1 evidenciado pela alta soroprevalência nessas condições. $\mathrm{Na}$ presença de fatores como número total de fêmeas superior a 100 e de ordenha mecânica, ocorreu a maior probabilidade, equivalente a $98,9 \%$ da ocorrência de infecções por BoHV-1, presumindo-se valores comuns para todas as outras variáveis avaliadas. Em rebanhos na Inglaterra, foi identificada que a maior taxa de soropositividade associada ao BoHV-1 estava relacionada ao tamanho do rebanho, possivelmente pelo fato de que, em rebanhos maiores, a chance de contato entre os animais aumenta, predispondo à transmissão (Woodbine et al., 2009).

No Brasil, Dias et al. (2013), ao empregarem uma amostragem muito diferenciada da que foi avaliada neste estudo, tanto com relação aos tipos de rebanhos e manejos quanto ao número de animais, também identificaram a reprodução por monta natural como um dos principais fatores de risco para infecção por BoHV-1 no estado do Paraná. Esse sistema aumenta a probabilidade de infecção em comparação à inseminação artificial, pois, nas centrais de processamento de sêmen bovino, por regulamentação nacional, são exigidas rigorosas normas de controle sanitário, com o objetivo de garantir a ausência de micro-organismos patogênicos no sêmen. A inseminação artificial também foi considerada um fator de proteção contra infecção por BoHV-1, quando utilizada com cuidado e isolada (Barbosa et al., 2005). Em vacas leiteiras na Colômbia, a reprodução por touros em contraposição à inseminação artificial também foi considerada como fator de risco associado à infecção por BoHV-1 e BVDV (Quevedo et al., 2011). 
Tabela 2. Distribuição percentual dos possíveis fatores de risco associados à soroprevalência por vírusneutralização para BoHV-1 e BVDV em vacas leiteiras mestiças não vacinadas, no município de Uberlândia, MG, Brasil

\begin{tabular}{|c|c|c|c|}
\hline Variáveis & $\begin{array}{c}\text { Animais } \\
\text { avaliados }\end{array}$ & $\begin{array}{c}\text { BoHV-1 } \\
\text { positivos/soroprevalência } \\
(\%) \\
\end{array}$ & $\begin{array}{c}\text { BVDV } \\
\text { positivos/soroprevalência (\%) }\end{array}$ \\
\hline \multicolumn{4}{|l|}{ Aptidão da fazenda } \\
\hline Leite & 211 & $132(62,6)$ & $95(45,0)$ \\
\hline Misto & 53 & $33(62,3)$ & $24(45,3)$ \\
\hline \multicolumn{4}{|l|}{ Total de fêmeas } \\
\hline$\leq 100$ & 239 & $145(60,7)$ & $107(44,8)$ \\
\hline$>100$ & 25 & $20(80,0)$ & $12(48,0)$ \\
\hline \multicolumn{4}{|l|}{ Total de fêmeas > 2 anos } \\
\hline$\leq 50$ & 180 & $114(63,3)$ & $79(43,9)$ \\
\hline$>50$ & 84 & $51(60,7)$ & $40(47,6)$ \\
\hline \multicolumn{4}{|l|}{ Total de animais } \\
\hline$\leq 100$ & 195 & $112(57,4)$ & $89(45,6)$ \\
\hline$>100$ & 69 & $53(76,8)$ & $30(43,5)$ \\
\hline \multicolumn{4}{|l|}{ Tipo de ordenha } \\
\hline Manual & 110 & $68(61,8)$ & $36(32,7)$ \\
\hline Mecânica & 154 & $97(63,0)$ & $83(53,9)$ \\
\hline \multicolumn{4}{|l|}{ Reprodução (IA) } \\
\hline Não & 177 & $122(68,9)$ & $83(46,9)$ \\
\hline Sim & 87 & $43(49,4)$ & $36(41.4)$ \\
\hline \multicolumn{4}{|l|}{ Reprodução (MN) } \\
\hline Não & 45 & $43(95,6)$ & $36(80.0)$ \\
\hline Sim & 219 & $122(55,7)$ & $83(37,9)$ \\
\hline \multicolumn{4}{|l|}{ Compra de animais } \\
\hline Não & 13 & $11(84,6)$ & $9(69,2)$ \\
\hline Sim & 251 & $154(61,4)$ & $110(43,8)$ \\
\hline \multicolumn{4}{|l|}{ Quarentena } \\
\hline Não & 222 & $139(62,6)$ & $103(46,4)$ \\
\hline Sim & 42 & $26(61,9)$ & $16(38,1)$ \\
\hline \multicolumn{4}{|c|}{ Abortamento - propriedade } \\
\hline Não & 40 & $24(60,0)$ & $16(40,0)$ \\
\hline Sim & 224 & $141(62,9)$ & $103(46,0)$ \\
\hline \multicolumn{4}{|l|}{ Piquete de parição } \\
\hline Não & 127 & $73(57,5)$ & $47(37,0)$ \\
\hline Sim & 137 & $92(67,2)$ & $72(52,6)$ \\
\hline \multicolumn{4}{|l|}{ Presença de ovelhas } \\
\hline Não & 238 & $149(62,6)$ & $108(45,4)$ \\
\hline Sim & 26 & $16(61,5)$ & $11(42,3)$ \\
\hline \multicolumn{4}{|c|}{ Presença de ruminantes selvagens } \\
\hline Não & 110 & $67(60,9)$ & $53(48,2)$ \\
\hline Sim & 154 & $98(63,6)$ & $66(42,9)$ \\
\hline \multicolumn{4}{|l|}{ Doenças respiratórias } \\
\hline Não & 250 & $159(63,6)$ & $113(45,2)$ \\
\hline Sim & 14 & $6(42,9)$ & $6(42,9)$ \\
\hline \multicolumn{4}{|l|}{ Abortamento - animal } \\
\hline Não & 250 & $154(61,6)$ & $112(44,8)$ \\
\hline Sim & 14 & $11(78,8)$ & $7(50,0)$ \\
\hline \multicolumn{4}{|l|}{ Repetição de cio - animal } \\
\hline Não & 253 & $158(62,5)$ & $115(45,5)$ \\
\hline Sim & 11 & $7(63,6)$ & $4(36,4)$ \\
\hline
\end{tabular}

A realização de compra de animais foi um fator que diminuiu o risco associado ao BoHV-1, o que poderia estar relacionado à reposição e renovação frequente do rebanho, mas sabe-se que há maior chance de adquirir animais portadores eliminando o vírus por secreções (Bezerra et al., 2012). Na Índia, Trangadia et al. (2010) reforçaram que a aquisição de animais 
sem triagem apropriada assim como a ausência de quarentena antes da incorporação ao rebanho principal também constituem fatores de risco relacionados com a alta prevalência de IBR nos rebanhos.

No México, fatores de risco associados à infecção por BoHV-1 foram encontrados em bovinos de dupla aptidão em relação ao gado de corte e em bovinos com seis anos de idade. A infecção também foi maior no grupo de animais representante de diferentes fases reprodutivas (gestantes e paridas) em comparação aos animais na puberdade. Nos animais de dupla aptidão, a inseminação artificial é raramente utilizada e, consequentemente, a monta natural poderia contribuir para a disseminação da doença (Romero-Salas et al., 2013).

Apesar de a aptidão do rebanho não ter sido um fator de risco associado à infecção por BoHV-1, Médici et al. (2000), ao compararem os resultados sorológicos obtidos em rebanhos de corte e de leite no estado do Paraná, observaram que a taxa de animais soropositivos para o BoHV-1 foi superior nos bovinos com aptidão para corte em relação aos bovinos leiteiros. Segundo os autores, as práticas de manejo intensivo das vacas leiteiras possibilitam maior facilidade de transmissão de várias enfermidades infecciosas, em relação aos bovinos criados extensivamente. Porém, a taxa de renovação de plantel na pecuária leiteira é muito superior à renovação observada na pecuária de corte. Com isso, a possibilidade de manutenção de vacas soropositivas por mais tempo em rebanhos de corte é superior, fazendo com que a taxa de infecção do rebanho total também seja superior.

Ainda no presente estudo, a prática frequente de não uso de quarentena para os animais recémadquiridos, a aptidão mista do rebanho e a presença de piquete parição, influenciaram nas taxas de soropositividade para o BVDV. No Brasil, variáveis como a utilização de piquetes separados para fêmeas nas fases de parto foram identificadas em rebanhos de corte e leite do Rio Grande do Sul (Quincozes et al., 2007). Em rebanhos bovinos dos estados de Minas Gerais e São Paulo, foi possível associar a infecção pelo BVDV independentemente da aptidão, da raça, do tamanho e do manejo dos rebanhos (Samara et al., 2004). Em vacas de leite na Colômbia, a aquisição de novos animais também foi considerada como fator de risco associada à infecção por BVDV (Quevedo et al., 2011).

A maior probabilidade de ocorrência do BVDV foi de $89,9 \%$, quando houve a influência dos fatores positivos (variáveis=1), presumindo valores comuns para todas as outras variáveis avaliadas, e não houve interferência da não utilização da inseminação artificial.

Para a infecção dupla, ou seja, rebanhos infectados simultaneamente por BoHV-1 e BVDV, foram identificados dois fatores de risco, como a presença de ordenha mecânica, que aumentou o risco em 3,36 vezes, e a realização de inseminação artificial, que reduziu o risco em $56,1 \%$ das propriedades. Identificou-se maior risco associado aos vírus BoHV-1/BVDV $(50,2 \%)$ somente quando a ordenha era mecanizada. A utilização de ordenha mecânica foi um fator de risco associado à infecção por BoHV-1, BVDV e também por ambos os vírus. $\mathrm{O}$ uso desse tipo de ordenha requer manejo mais intensivo dos animais, aspecto que poderia aumentar a probabilidade de transmissão viral (Quincozes et al., 2007).

Nos rebanhos avaliados, que representam as condições de produção da maioria dos rebanhos de bovinos leiteiros da região do Triângulo Mineiro, as taxas de soroprevalência encontradas para infecções por BoHV-1 (62,5\%) e por BVDV $(45,1 \%)$ são muito próximas às identificadas em vários estudos soroepidemiológicos realizados em amostragens aleatórias obtidas em praticamente todas as regiões geográficas brasileiras (Flores et al., 2005; Alexandrino et al., 2011). A região do Triângulo Mineiro, onde está localizado o município de Uberlândia, tem grande importância na pecuária de corte e leiteira. No município, a produção de leite é realizada principalmente em pequenas propriedades, onde prevalece a criação de animais cruzados em regime extensivo. $\mathrm{Na}$ maioria dos rebanhos, informações epidemiológicas sobre a presença de importantes infecções que comprometem a saúde animal são desconhecidas, assim como os fatores de risco mais associados a essas infecções.

Em 2006, Mineo e colaboradores, em um levantamento sorológico, realizado na região do Triângulo Mineiro, identificaram taxas de 39 e $49 \%$ de anticorpos anti-BoHV-1 e BVDV, respectivamente, em rebanhos de vacas leiteiras 
com histórico de problemas reprodutivos. Considerando o impacto dessas duas viroses na saúde geral e reprodutiva dos rebanhos bovinos e com o intuito de atualizar a frequência desses agentes virais nessa importante bacia leiteira brasileira, o presente estudo buscou avaliar, de forma mais consistente, os principais fatores que pudessem constituir risco sanitário para IBR e BVDV, no contexto do sistema produtivo local. Com isso, medidas de mitigação de risco de infecção poderão ser adotadas, com o objetivo de reduzir o impacto econômico dessas duas viroses, particularmente na esfera reprodutiva de fêmeas bovinas leiteiras.

\section{CONCLUSÃO}

Os resultados deste estudo, realizado em rebanhos leiteiros em regime de criação extensivo, com histórico de problemas reprodutivos e com manejo sanitário que não inclui a vacinação para controle de IBR e BVD, demonstram que ambas as infecções estão amplamente disseminadas nos rebanhos leiteiros do município de Uberlândia. Essas condições possibilitaram utilizar essas duas viroses como modelo para identificação de fatores de risco associados às infecções por BoHV-1 e BVDV nesse sistema de criação loco regional. Observou-se que variáveis como tamanho do rebanho e presença de ordenha mecânica constituem importantes fatores de risco para essas infecções virais que impactam a reprodução. Com isso, além da implantação de um programa de vacinação para controle de IBR e BVD, o programa sanitário do rebanho deve incluir a adoção de medidas de manejo focadas nas principais variáveis identificadas neste estudo, com o objetivo de mitigar riscos sanitários que facilitam a transmissão e, principalmente, a disseminação dessas viroses nos rebanhos bovinos leiteiros.

\section{REFERÊNCIAS}

ALEXANDRINO, B.; DIAS, F.C.; OLIVEIRA, M.C. et al. Herpesvirus bovino associado à diarréia viral bovina e à leucose enzoótica bovina. Ars Vet., v.27, p.168-174, 2011.

BARBOSA, A.C.V.C.; BRITO, W.M.E.; ALFAIA, B.T. Soroprevalência e fatores de risco para a infecção pelo herpesvírus bovino tipo 1 (BHV-1) no estado de Goiás, Brasil. Ciênc. Rural, v35, p.1368-1373, 2005.
BEZERRA, D.C.; CHAVES, N.P.; SOUSA, V.E. et al. Prevalência e fatores de risco associados à infecção pelo herpesvírus bovino tipo 1 em rebanhos bovinos leiteiros no estado do Maranhão. Rev. Bras. Ciênc. Vet., v.19, p.158162, 2012.

BRASIL. Ministério da Agricultura, Pecuária e Abastecimento. Disponível em: <http://www.agricultura.gov.br>. Acessado em: 22 abril de 2019.

CHAVES, N.P.; BEZERRA, D.C.; SOUSA, V.E.; SANTOS, H.P. Frequency of antibodies and risk factors of bovine viral diarrhea virus infection in non-vaccinated dairy cows in the Maranhense Amazon region, Brazil. Ciênc. Rural, v.40, p.1448-1451, 2010.

COWLEY, D.J.B.; GRAHAM, D.A.; GUELBENZU, M. et al. Aspects of bovine herpesvirus 1 and bovine viral diarrhoea virus herd-level seroprevalence and vaccination in dairy and beef herds in Northern Ireland. Ir. Vet. J., v.67, p.1-5, 2014.

DEZEN, S.; OTONEL, R.A.A.; ALFIERI, A.F. et al. Perfil da infecção pelo vírus da diarreia viral bovina (BVDV) em um rebanho bovino leiteiro de alta produção e com programa de vacinação contra o BVDV. Pesqui. Vet. Bras., v.33, p.141-147, 2013.

DIAS, J.A.; ALFIERI, A.A.; FERREIRANETO, J.S. et al. Seroprevalence and risk factors of bovine Herpesvirus 1 infection in cattle herds in the state of Paraná, Brazil. Transbound. Emerg. Dis., v.60, p.39-47, 2013.

ESTATÍSTICA de pecuária municipal. 2017. Disponível em: <http://ftp.ibge.gov.br/Producao_Pecuaria/Fascic ulo_Indicadores_IBGE/abate-leite-couro-

ovos_201604caderno.pdf>. Acessado em: 15 maio 2017.

FLORES, E.F.; WEIBLEN, R.; VOGEL, F.S.F. et al. A infecção pelo vírus da diarréia viral bovina (BVDV) no Brasil: histórico, situação atual e perspectivas. Pesqui. Vet. Bras., v.25, p.125-134, 2005.

HAIR, J.F.; BLACK, W.C.; BABIN, B.J. et al. Multivariate data analysis. 6.ed. London: Pearson Prentice Hall, 2006. 761p. 
HOSMER, D.W.; LEMESHOW, S. Applied logistic regression 1. New York: WileyInterscience Publication, 2004. 397p.

MÉDICI, K.C.; ALFIERI, A.A.; ALFIERI, A.F. Prevalência de anticorpos neutralizantes contra o herpesvírus bovino tipo 1 , decorrente de infecçäo natural, em rebanhos com distúrbios reprodutivos. Ciênc. Rural, v.30, p.347-350, 2000.

MINEO, T.W.P.; ALENIUS, S.; NASLUND, K. et al. Distribution of antibodies against Neospora caninum, BVDV and BHV-1 among cows in brazilian dairy herds with reproductive disorders. Rev. Bras. Parasitol. Vet., v.15, p.188, 2006.

NANDI, S.; KUMAR, M.; MANOHAR, M.; CHAUHAN, R.S. Bovine herpes virus infections in cattle. Anim. Health Res. Rev., v.10, p.85-98, 2009.

MANUAL of diagnostic tests and vaccines for terrestrial animals. [Paris]: OIE, 2015. Available in: <http://www.oie.int/manual-of-diagnostic tests-and-vaccines-for-terrestrial-animals/>.

Accessed in: 28 Feb. 2016.

MAPA

QUEVEDO, D.C.; BENAVIDES, B.B.; CÁRDENAS, G.; HERRERA, C. Seroprevalence and risk factors associated to BHV-1 and DVBV in dairy herds in Pasto, Colombia, in 2011. Rev. Lasallista. Invest., v.8, p.61-68, 2011.

QUINCOZES, C.G.; FISCHER, G.; HUBNER, $\mathrm{S}$. O et al.. Prevalência e fatores associados à infecção pelo vírus da diarréia viral bovina na região Sul do Rio Grande do Sul. Semin. Ciênc. Agrar., v.28, p.269-276, 2007.

ROMERO-SALAS, D.; AHUJA-AGUIRRE, C.; MONTIEL-PALACIOS, F. et al. Seroprevalence and risk factors associated with infectious bovine rhinotracheitis in unvaccinated cattle in southern Veracruz. Afr. J. Microbiol. Res., v.7, p.17161722, 2013.
SAMARA, S.I.; DIAS, F.C.; MOREIRA, S.P.G. Ocorrência da diarréia viral bovina nas regiões sul do Estado de Minas Gerais e nordeste do Estado de São Paulo. Braz. J. Vet. Res. Anim. Sci., v.41, p.396-403, 2004.

SEGURA-CORREA, J.C.; ZAPATA-CAMPOS, C.C.; JASSO-OBREGÓN, J.O. et al. Seroprevalence and risk factors associated with bovine herpesvirus 1 and bovine viral diarrhea virus in North-Eastern Mexico. Open Vet., v.6, p.143-149, 2016.

SILVA, G.J.C.; SOUZA, E.C.; MARTINS, H.E.P. Produção agropecuária em municípios de Minas Gerais (1996-2006): padrões de distribuição, especialização e associação espacial. Rev. Econ. Sociol. Rural, v.50, p.333349, 2012.

SOUSA, V.E.; BEZERRA, D.C.; CHAVES, N.P. et al. Frequência de anticorpos e fatores de risco associados à infecção pelo vírus da diarréia viral bovina (BVDV) e herpesvírus bovino tipo 1 (BoHV-1) em fêmeas bovinas leiteiras criadas em sistema de produção semi-intensivo. Rev. Bras. Med. Vet., v.35, p.21-25, 2013.

SWEENEY, D.J.; WILLAMS, T.A.; ANDERSON, D.R. Estatística aplicada à administração e economia. 3.ed. São Paulo: Cengage Learning, 2013. 720p.

TRANGADIA, B.; RANA, S.K.; MUKHERJEE, F.; SRINIVASAN, V.A. Prevalence of brucellosis and infectious bovine rhinotracheitis in organized dairy farms in India. Trop. Anim. Health Prod., v.42, p.203-207, 2010.

USDA foreign agricultural service. Washington: USDA, 2015. Available in: <http://apps.fas.usda.gov/psdonline/>. Accessed in: 15 Jan. 2015.

WOODBINE, K.A.; MEDLEY, G.F.; MOORE, S.J. et al. A four year longitudinal seroepidemiological study of bovine herpesvirus type-1 (BHV-1) in adult cattle in 107 unvaccinated herds in south west England. Vet. Res., v.5, p.1-12, 2009. 